\title{
Sport Sentiments and Stock Returns: Example of FIFA World Cups
}

\author{
Jen-Sin Lee ${ }^{1}$, Ching-Wei Chiu ${ }^{2}$ \\ ${ }^{1}$ Department of Finance, I-Shou University, Taiwan \\ ${ }^{2}$ Postgraduate Program of Management, I-Shou University, Taiwan \\ Correspondence: Jen-Sin Lee, Department of Finance, I-Shou University, Taiwan.
}

Received: November 10, 2016

doi:10.11114/aef.v4i2.2108

\author{
Accepted: November 24, $2016 \quad$ Available online: December 26, 2016 \\ URL: http://dx.doi.org/10.11114/aef.v4i2.2108
}

\begin{abstract}
This paper investigates the relation between sport sentiments and excess stock returns, and our data is from the $17^{\text {th }}$ to $20^{\text {th }}$ FIFA World Cups. Many studies find the relation between sport sentiments and stock market returns. In contrast to the previous studies, this paper considers seven conditions: (1) Considering stock markets are efficient markets, this paper uses not only close price but also open price to estimate excess stock returns which is affected by game results; (2) This paper further considers that sport sentiments affect sponsors' excess stock returns (this point is seldom discussed by the past literature); (3) This paper further considers a time-lagged effect between sport sentiments and excess stock returns. (4) This paper further considers the persistent effect of previous games result. (5) This paper further employs the samples by not only for all participant countries but also for the each of participant countries. (6) This paper further considers the conditions of extreme wins and extreme loses. (7) This paper further considers the samples of championship games to exam the relation between sport sentiments and excess stock returns. Our results find that sport sentiments does not affect stock market returns, the reason is that investors are rational in dealing with sport sentiments (FIFA World Cup) and the stock trading decisions. This paper further finds Sponsors effect hypothesis: A significant positive/ negative effect on sponsors' excess stock returns after wins/ loses in the championship games, and this effect only occurs on the open price of the next trading day. These empirical results can offer an important information for the investors of sport sponsor stocks.
\end{abstract}

Keywords: sport sentiments, stock returns, open price, sponsor, sponsors effect hypothesis

\section{Introduction}

This paper investigates the relation between sport sentiments and excess stock returns, and our data is from the 17th to 20th FIFA World Cups. Many studies find the relation between sport sentiments and stock market returns. In contrast to the previous studies, this paper considers seven conditions: (1) Considering stock markets are efficient markets, this paper uses not only close price but also open price to estimate excess stock returns (affected by game results); (2) This paper further considers that sport sentiments affect sponsors' excess stock returns (this point is seldom discussed by the past literature); (3) This paper further considers a time-lagged effect between sport sentiments and excess stock returns. (4) This paper further considers the persistent effect of previous games result. (5) This paper employs the samples by not only for all participant countries but also for the each of participant countries. (6) This paper further considers the conditions of extreme wins and extreme loses. (7) This paper further considers the samples of championship games to exam the relation between sport sentiments and excess stock returns.

The FIFA World Cup is the most crucial event and soccer is the most popular sport. According to a report from the Hudson company in 2006, in England, 70\% of men and 62\% of women said that the upcoming 2006 World Cup would have an effect on their working lives (http://www.sirc.org/publik/sport_and_the_workplace.pdf). Based on a report by the ING company in 2010, $40 \%$ of office workers took a day off or left early to watch the live broadcast of the quarter-final in the 2010 FIFA World Cup.

Many studies report on the influence of the results of sports matches' on stock market returns (Edmans et al., 2007; Palomino et al., 2009; Wann et al., 1993). Why do the emotions elicited from internal sports results affect the stock price? Multiple past studies, psychological factors are often considered as crucial determinants of asset pricing, and the sentiment of investors tends to affect their evaluations of future prospects and in turn their trading behaviour in financial markets (Stracca, 2004). Madrigal (2001) and Wann and Branscombe (1993) suggest that team identification depends 
on an individual level of attachment to or concern about a particular sports team. For the most strongly attached people, a sports team represents a particularly salient self-identity from which considerable ego enhancement is derived (Cialdini et al., 1976). Yu and Yuan (2011), investors are sentiment traders in a volatile period, stated that '... sentiment traders tend to be inexperienced and naïve investors, they are likely to have poor understanding of how to measure risk' (p. 368).

Many studies find that the impact of soccer results on stock returns shows different conclusions, such as symmetric effect (Ashton et al., 2003, 2010; Berument et al., 2013; Fung et al., 2015), asymmetric effect (Chang et al., 2012; Edmans et al., 2007; Hanke and Kirchler, 2013) and insignificant effect (Gerlach, 2011; Kaplanski and Levy, 2010; Klein et al., 2009). Edmans et al. (2007) reveals an asymmetric effect, in which loses have a significant negative effect on the losing countries' local markets, whereas victories do not have a significant effect. Klein et al. (2009) proposes that there is no connection between a specific national soccer team's victory or lose and stock returns. According to previous studies, the relation between sport sentiments and stock market returns is asymmetric and inconsistent. Therefore, this paper considers internal sports results as the proxy variable of sport sentiments to investigate the relation between sport sentiments and excess stock returns of local stock markets (hereafter excess stock returns).

This paper extends the study by Edmans et al. (2007), and in contrast to their study, this paper further considers seven conditions: (1) Considering stock markets are efficient markets, this paper uses not only close price but also open price to estimate excess stock returns: Edmans et al. (2007) just uses close price to estimate excess stock returns which are affected by sport sentiments, however, this paper uses not only close price but also open price to estimate excess stock returns, why does this paper use open price to estimate it? Because the stock market is efficiency enough to react any information on the stock market rapidly. For example, if teams win the soccer game at night on day $\mathrm{t}$ (most of matches of FIFA World Cup start at night basically), the information of win must has a reaction on the open price on day $t+1$ when the stock market open. (2) This paper further considers that sport sentiment affect sponsors' excess stock returns: Sport sentiments may have significant effect on the excess stock returns of the sponsors companies. Furthermore, the effect of sport sentiments will be diluted when this paper focuses on the whole stock market. Therefore, sport sentiments has a strong effect on sponsors' excess stock returns, instead of the excess stock returns of whole stock market. (3) This paper further considers a time-lagged effect between sports sentiment and excess stock returns. (4) This paper further considers the persistent effect of previous games result. (5) This paper further considers the samples include all participant countries and each of participant countries. (6) This paper further considers the conditions of extreme wins and extreme loses. (7) This paper further considers the samples of championship games to exam the relation between sport sentiments and excess stock returns: Because the fans always care about that their favourite team get the champion or not, the effect of win or lose in championship game has more reaction than other games. There is a strong effect of sport sentiments in championship game.

Hanke and Kirchler (2013) study the impact of soccer results on sport sponsors' excess stock returns, and they present asymmetric effects, in which a negative impact on sponsor's excess stock returns after loses, but there is insignificant positive effect after victories, their conclusion is similar with Edmans et al. (2007). No matter how the past studies try to understand the relation between sport sentiments and excess stock returns, but the past studies find an inconsistent relation between sport sentiments and excess stock returns. However, this paper suggests that the reason of leading this inconsistent results is the past literature only using close price to calculate the excess stock returns. According to efficient market hypothesis, this paper argues that excess stock returns fully reflect all available information on a particular stock market at any given time, in addition, sport sentiments is a fleeting effect, and the it only has the impact on the open price of next trading day immediately. Hence, this paper tries to use open price to estimate excess stock returns and sport sponsor's excess stock returns.

The findings are different among Edmans et al. (2007), Hanke and Kirchler (2013), and this paper. Edmans et al. (2007) and Hanke and Kirchler (2013) reveal an asymmetric effect, in which loses have a significant negative effect on the losing countries' local markets, whereas wins do not have a significant effect. This paper finds a significant positive effect on sponsors' excess stock returns after wins and a significant negative effect on sponsors' excess stock returns after loses in the championship games, and this effect only occurs on the open price of the next trading day. For instance, the championship game of $17^{\text {th }}$ FIFA World Cup was started in June $30^{\text {th }} 2002$ evening, the match was played by Brazil and Germany, and Brazilian team won the champion in the end. The sport (sponsor) company of Brazilian team was Nike, and Nike's excess stock return of open price on first trading day after victory rose 1.3 percent, but Nike's excess stock return of open price on second trading day was zero, which means sport sentiments is an efficient and quick effect, and only occurs on the open price of the next trading day, sport sentiments is likely not to be a persistent effect on the stock market.

\section{Literature Review and Hypothesis Development}

People experience strong emotional outcomes when their favourite sports team wins or loses. Previous studies show that 
internal sports results generally have a significant effect on mood (Edmans et al., 2007; Arkes et al., 1988; Schweitzer et al., 1992). People feel positive when their favourite country wins and negative when their favourite country loses (Hirt et al., 1992). Edmans et al. (2007) revealed a strong association between the results of soccer games and excess stock returns and identified an asymmetric effect through which loses have a significant negative effect on the losing countries' local stock markets, whereas victories do not have a significant positive effect. According to aforementioned studies, this paper proposes Hypothesis 1 as follows:

Asymmetric effect hypothesis: Loses have a significant negative effect on countries' local stock markets, whereas victories do not have a significant positive effect on countries'local stock markets.

In this hypothesis, this paper controls the effect of the previous game result. Kahneman and Tversky (1979) suggest that the prospect theory is reliance on gains and loses as carriers of utility, rather than wealth levels. An crucial determinant of utility is the reference point against which gains and loses are measured. Wann et al. (1994) document that fans often experience a strong positive reaction when their team performs well and a corresponding negative reaction when the team performs poorly. In our settings, the reference point is supporters' pre-game expectations of how their team will perform. Several studies show that fans are subject to an 'allegiance bias', whereby individuals who are psychologically invested in a desired outcome generate biased predictions (Markman and Hirt, 2002; Wann et al., 2001). Thus, this paper may find a greater stock price reaction after loses than after wins if the reference point of soccer fans is that their team will win. As mentioned previously, this paper controls the effect of the previous game result. Thus, this paper proposes Hypothesis 2 as follows:

Persistent effect hypothesis: There is a significant market decline after a soccer lose, particularly when a country won the previous games; the stock market is positively affected after a soccer win, particularly when a country lose the previous games.

From this paper observed, this paper takes the championship game of $17^{\text {th }}$ FIFA World Cup for example, Nike was the sport sponsor company of the champion (Brazil), and the Nike's excess stock return of open price on first trading day after victory rose 1.3 percent, but zero percent on second trading day, which means sport sentiments is an efficient and quick effect, and only occurs on the open price of the next trading day, sport sentiments is likely not to be a persistent effect on the stock market. Therefore, this paper proposes that investors are rational in dealing with sport sentiments (FIFA World Cup) and the stock portfolio. This means that although fans feel depressed after their favourite team is eliminated, they would not make an irrational decision to lose their money on the stock market. Hanke and Kirchler (2013) suggests that there is a negative impact on the sport sponsors' stock excess returns (close price) after a lose. This paper argues that the results of a championship games of FIFA World Cup strongly affect the excess stock returns of the sport (sponsors) companies, instead of local stock market returns, moreover, sport sentiments only has an impact on the open price of next trading day. So this paper proposes Hypothesis $\mathbf{3}$ as follows:

Sponsors effect hypothesis: A significant positive effect on sponsors' excess stock returns after wins and a significant negative effect on sponsors' excess stock returns after loses in the championship games, and this effect only occurs on the open price of next trading day.

\section{Description of Equations and Variables}

Edmans et al. (2007) examine the effect of excess stock returns when a team wins or loses the game in the FIFA World Cup, and control the effects of wins and loses, the weekly effect $\left(D_{t}\right)$, and the non-weekend holidays effect $\left(Q_{t}\right)$, the equation which is first constructed by Edmans et al. (2007) present as follows:

$$
R_{i t}=\sum \gamma_{0}+\gamma_{1} R_{i t-1}+\gamma_{2} R_{m t-1}+\gamma_{3} R_{m t}+\gamma_{4} R_{m t+1}+\gamma_{5} D_{t}+\gamma_{6} Q_{t}+\varepsilon_{i t}
$$

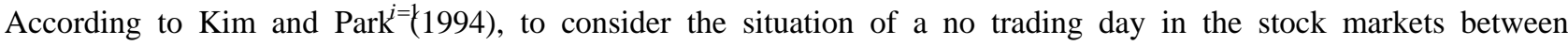
participant countries and U.S. (or U.K. when U.S. is the participant country) that this paper sets a dummy variable of a no trading day. This also controls the effects of excess stock returns rises and slumps. We adopt the model of Edmans et al. (2007) and treatment of no trading day of Kim and Park (1994) to revise the equation (1) to equation (2). First, this paper examines the following equation for each country:

$$
R_{i t}=\sum \gamma_{0}+\gamma_{1} R_{i t-1}+\gamma_{2} R_{m t-1}+\gamma_{3} R_{m t}+\gamma_{4} R_{m t+1}+\gamma_{5} D_{t}+\gamma_{6} Q_{t}+\gamma_{7} D_{u s, u p}+\gamma_{8} D_{u s, \text { down }}+\gamma_{9} D_{c, \text { up }}+\gamma_{10} D_{c, \text { down }}+\varepsilon_{i t}
$$

In this equation, the time series of excess stock returns to the extent of international stock markets are integrated, and the excess stock returns are correlated across countries (Edmans et al., 2007). In equation (2), $R_{i t}$ is the continuously compounded daily excess stock returns for country $i$ on day $t ; R_{i t-1}$ is the lagged excess stock returns; $R_{m t}$ is the continuously compounded daily U.S. Dow Jones excess stock returns (or U.K. excess stock returns when U.S. is the participant country) on day $t ; R_{m t-1}$ and $R_{m t+1}$ are some local stock markets that may involve a lagging index and leading index in the world stock market; $D_{t}$ is the dummy variable for Monday to Thursday, $Q_{t}$ is the dummy variable for days for which the previous one through five days are non-weekend holidays. $D_{u s, u p}$ and $D_{u s, \text { down }}$ are the dummy variables for 
the trading day of U.S. stock market and the excess stock returns rise and slump respectively (other participant countries' stock markets have no trading day); and $D_{c, u p}$ and $D_{c, \text { down }}$ are the dummy variables for the trading day of participant countries and the excess stock returns rise and slump respectively (the U.S. stock market has no trading day).

According to Edmans et al. (2007), this paper simultaneously examines the equation for all participant countries by interacting each independent variable with a set of country dummies. Let $\varepsilon_{i t}$ be the residuals from equation (2). This paper determines the effect of the outcome of FIFA World Cup matches by using the following equation:

$$
\varepsilon_{i t}=\sum_{i=1}^{t} \beta_{0}+\beta_{W} W_{i t}+\beta_{L} L_{i t}+u_{i t}
$$

This paper simultaneously analyses the effects of wins ${ }^{1}$ and loses, and to avoid the problem of linear combination, this paper uses the proportions of wins and loses as our win and lose dummy variables, instead of zero and one (Lee, Shen, and Yen, 2010), where $W_{i t}$ is the dummy variable of a win which is the proportion of a win if a country wins a game (otherwise, it is zero), and $L_{i t}$ is the dummy variable of a lose, which is the proportion of a lose if a country loses the game (otherwise, it is zero). For instance, in a game of participant countries A and B, when the game result is 3:2, the dummy variable of the win for participant country A is one-third (i.e. the dummy variable of the loss is $1-(2 / 3)$ ).

The methods to verify the hypotheses are as follows: This paper divides the excess stock returns data of all participant countries into two groups, win and lose. This paper uses these groups to analyse the effects of stock markets in the situations of a win $\left(\beta_{W}\right)$ and a lose $\left(\beta_{L}\right)$ (equation (3)). If Asymmetric effect hypothesis is supported, $\left|\beta_{W}\right|$ must be lower than $\left|\beta_{L}\right|$.

This paper then divides the data of win into two groups, the previous game is win or lose. This paper uses these groups to analyse the effects of stock markets in the situation of this game is win and the previous games is win $\left(\beta_{W W}\right)$ or lose $\left(\beta_{W L}\right)$ (equation (3)). If the Persistent effect hypothesis is supported, $\left|\beta_{W W}\right|$ must be lower than $\left|\beta_{W L}\right|$. In addition, this paper divides the data of lose into two groups, the previous games is win or lose. This paper uses these groups to analyse the effects of stock markets in the situations of this game is lose and previous games is win $\left(\beta_{L W}\right)$ or lose $\left(\beta_{L L}\right)$ (equation (3)). If the Persistent effect hypothesis is supported, $\left|\beta_{L W}\right|$ must be higher than $\left|\beta_{L L}\right|$.

In the dependent variable of equation (2), this paper not only uses excess stock returns $(E R)$, but also considers four situations of MAR to analyse the equation:

$$
\begin{gathered}
E R=R R-R_{f} \\
M A R \_U S=R R-R R_{U S} \\
M A R \_b e t a \_U S=R R-\beta_{U S} R R_{U S} \\
M A R \_M S C I=R R-R R_{M S C I} \\
M A R \_ \text {beta_MSCI }=R R-\beta_{M S C I} R R_{M S C I}
\end{gathered}
$$

In the equation (4) which is the original estimation method, $R R$ is the raw returns of local stock markets, and $r_{f}$ is the risk-free rate, which is used as the interest rate of U.S. treasury bills (or U.K. treasury bills when the participant country in U.S.); $R R$ in equations (5) and (6) is the difference between $R R$ of local stock markets and $R R$ of U.S. Dow Jones stock index, and $R R$ in equations (7) and (8) is the difference between $R R$ of local stock markets and $R R$ of MSCI world index.

However, this paper cannot find significant effects on the empirical results to support our hypothesis derived from the aforementioned methods. This paper argues that the results of the FIFA World Cup possibly have strong effect on championship games and the stock price of the team's sport (sponsors) companies, instead of local stock market returns. This paper suggests that the stock market is efficient to react any information rapidly in the stock market, and most games end before the stock market opens. Therefore, this paper uses not only the close price but also the open price to estimate the excess stock returns. The main variables which this paper adopted are $R R$ and MAR.

This paper not only uses the close price but also the open price to calculate the excess stock returns and adjusted excess stock returns. The calculation methods are as follows:

$$
\begin{aligned}
& R R_{\text {close }}=\left(\text { close }_{\text {price }}-\text { close } \text { price } t_{t-1}\right) / \text { close }_{\text {price }}{ }_{t-1} \\
& R R_{\text {open }}=\left(\text { open }_{\text {price }}-\text { close price }_{t-1}\right) / \text { close }_{\text {price }} \text { t-I }_{1} \\
& M A R=R R-R R_{U S}
\end{aligned}
$$

\section{Data Description}

The most popular sport in the world is soccer, the FIFA World Cup is the most prominent sport game. Soccer plays a crucial role in many soccer fans' lives, and this study reveal how the FIFA World Cup affects sport sentiments and excess stock returns. This paper uses the data of $17^{\text {th }}-20^{\text {th }}$ FIFA World Cup (2002-2014), because the website of the 
FIFA World Cup $^{1}$ offers only the data of the matches from 2002 onwards. Therefore, this paper uses the data from the FIFA World Cup in 2002, 2006, 2010, and 2014 (see Table 1). The main variables include local stock excess returns, excess market returns, and adjusted market returns, these variables require the local stock price and risk-free rate.

Table 1. The data of FIFA World Cups

\begin{tabular}{ccccc}
\hline $\begin{array}{c}\text { FIFA } \\
\text { World Cups }\end{array}$ & Game Date & $\begin{array}{c}\text { Sponsored } \\
\text { Country }\end{array}$ & $\begin{array}{c}\text { Number of } \\
\text { Countries }\end{array}$ & $\begin{array}{c}\text { Real Number of } \\
\text { Countries }\end{array}$ \\
\hline $17^{\text {th }}$ & $2002 / 5 / 31 \sim 2002 / 6 / 30$ & Japan, Korea & 32 & 19 \\
$18^{\text {th }}$ & $2006 / 6 / 9 \sim 2006 / 7 / 10$ & Germany & 32 & 19 \\
$19^{\text {th }}$ & $2010 / 6 / 11 \sim 2010 / 7 / 11$ & South Africa & 32 & 20 \\
$20^{\text {th }}$ & $2014 / 6 / 12 \sim 2014 / 6 / 13$ & Brazil & 32 & 20 \\
\hline
\end{tabular}

Description: Real number of countries exclude the country that has no stock market of its own. The data sources are obtained from FIFA.

This paper argues that the results of the FIFA World Cup have a strong effect on the championship games and the stock price of the team's sport sponsor companies, instead of local stock market returns (see Table 2 and 3).

Table 2. The data of championship games

\begin{tabular}{cccc}
\hline Year & Host & Game Date & Championship Games \\
\hline $17^{\text {th }}$ & Koran and Japan & 30. June 2002 & Brazil vs. Germany \\
$18^{\text {th }}$ & Germany & 9. July 2006 & Italy vs. France \\
$19^{\text {th }}$ & South Africa & 11. July 2010 & Spain vs. Netherlands \\
$20^{\text {th }}$ & Brazil & 13. July 2014 & German vs. Argentina \\
\hline
\end{tabular}

Table 3. The data of Sponsors in championship games

\begin{tabular}{ccccc}
\hline Final Game & Win & Sponsors & Loss & Sponsors \\
\hline $17^{\text {th }}$ & Brazil & Nike & Germany & Adidas \\
$18^{\text {th }}$ & Italy & Puma & France & Nike \\
$19^{\text {th }}$ & Spain & Adidas & Netherlands & Nike \\
$20^{\text {th }}$ & Germany & Adidas & Argentina & Adidas
\end{tabular}

Description: This paper does not consider the $20^{\text {th }}$ FIFA World Cup (2014) in estimating the effect of sport sentiments on sponsors' excess stock returns, because Germany and Argentina had the same sponsors.

Analysing Asymmetric effect hypothesis. First, this paper divides the data into two groups, win and lose. This paper then simultaneously uses close and open prices as our variables, and uses $E R$ and MAR as our dependent variables in equation (1).

For estimating Persistent effect hypothesis, this paper divides the data of wins and loses into four groups (i.e. (1) the previous games is win and this game is win; (2) the previous games is win and this game is lose; (3) the previous games is lose and this game is win; and (4) the previous games is lose and this game is lose), and use these four groups to estimate the effects of stock markets in the situations if the previous games is win or lose and this game is win or lose.

This paper argues that the results of the FIFA World Cup strongly affected the championship games and the stock price of a team's sport (sponsors) companies, instead of local stock market return. Therefore, this paper investigates the relation between the results of the championship games and sponsors' excess stock returns for estimating Sponsors effect hypothesis. This paper selects 10 trading days before and after the championship game day by using close and open prices to estimate the raw return and adjusted market return. This paper track the stock volatility for the first and second trading days after the championship game day, and 10, 20, and 40 days after the championship game day.

\section{Empirical Results}

This paper analyses Asymmetric effect hypothesis by using equations (2) and (3), and use excess stock returns (ER) as dependent variable of equation (2), and separately uses close price of Dow Jones index and MSCI world index to

\footnotetext{
${ }^{1}$ http://www.fifa.com/index.html.
} 
estimate $R_{m t-l}, R_{m t}$, and $R_{m t+l}$. This paper divides the data into two groups, win and lose, and put the data into the equation. If Asymmetric effect hypothesis is supported, $\left|\beta_{W}\right|$ must be lower than $\left|\beta_{L}\right|$. However, most $\left|\beta_{W}\right|$ are higher than $\left|\beta_{L}\right|$ with insignificant, and therefore the results do not support Asymmetric effect hypothesis (see Table 4 and 5).

$$
\begin{gathered}
E R=R R-R_{f} \\
R_{i t}=\sum_{i=1}^{t} \gamma_{0}+\gamma_{1} R_{i t-1}+\gamma_{2} R_{m t-1}+\gamma_{3} R_{m t}+\gamma_{4} R_{m t+1}+\gamma_{5} D_{t}+\gamma_{6} Q_{t}+\gamma_{7} D_{u s, u p}+\gamma_{8} D_{u s, d o w n}+\gamma_{9} D_{c, u p}+\gamma_{10} D_{c, d o w n}+\varepsilon_{i t} \\
\varepsilon_{i t}=\sum_{i=1}^{t} \beta_{0}+\beta_{W} W_{i t}+\beta_{L} L_{i t}+u_{i t}
\end{gathered}
$$

Table 4. Empirical results of $E R$ by close price (asymmetric effect)

\begin{tabular}{ccc}
\hline & $\operatorname{Win}\left(\beta_{W}\right)$ & Lose $\left(\beta_{L}\right)$ \\
\hline \multirow{2}{*}{$17^{\text {th }}$} & Panel A - DV: ER_US & \\
& 0.01 & $4 . \mathrm{E}-03$ \\
$18^{\text {th }}$ & $(0.14)$ & $(0.31)$ \\
& $1 . \mathrm{E}-04$ & $-4 . \mathrm{E}-03$ \\
$19^{\text {th }}$ & $(0.96)$ & $(0.23)$ \\
& $2 . \mathrm{E}-03$ & $-1 . \mathrm{E}-03$ \\
$20^{\text {th }}$ & $(0.42)$ & $(0.59)$ \\
& 0.02 & $-3 . \mathrm{E}-03$ \\
& $(0.16)$ & $(0.33)$ \\
$18^{\text {th }}$ & Panel B - DV: ER_MSCI & \\
& 0.89 & 0.96 \\
$19^{\text {th }}$ & $(0.00)$ & $(0.00)$ \\
& 0.99 & 0.88 \\
$20^{\text {th }}$ & $(0.00)$ & $(0.00)$ \\
& 0.81 & 0.73 \\
& $(0.00)$ & $(0.00)$ \\
\hline
\end{tabular}

Description: MSCI world index was established in 2003, therefore, we cannot obtain the 2002 data.

In addition, this paper considers four situations of MAR to evaluate Asymmetric effect hypothesis. This paper uses MAR as dependent variable of equation (2), and separately uses close price of Dow Jones index and MSCI world index to estimate $R_{m t-l}, R_{m t}$, and $R_{m t+1}$. Although, most $\left|\beta_{L}\right|$ are higher than $\left|\beta_{W}\right|$, the $t$-values are insignificant, and this result still do not support Asymmetric effect hypothesis (see Table 5).

$$
\begin{gathered}
M A R \_U S=R R-R R_{U S} \\
M A R \_b e t a \_U S=R R-\beta_{U S} R R_{U S} \\
M A R \_M S C I=R R-R R_{M S C I} \\
M A R \_ \text {beta_MSCI }=R R-\beta_{M S C I} R R_{M S C I} \\
R_{i t}=\sum_{i=1}^{t} \gamma_{0}+\gamma_{1} R_{i t-1}+\gamma_{2} R_{m t-1}+\gamma_{3} R_{m t}+\gamma_{4} R_{m t+1}+\gamma_{5} D_{t}+\gamma_{6} Q_{t}+\gamma_{7} D_{u s, u p}+\gamma_{8} D_{u s, \text { down }}+\gamma_{9} D_{c, u p}+\gamma_{10} D_{c, d o w n}+\varepsilon_{i t} \\
\varepsilon_{i t}=\sum_{i=1}^{t} \beta_{0}+\beta_{W} W_{i t}+\beta_{L} L_{i t}+u_{i t}
\end{gathered}
$$


Table 5. Empirical results of $M A R$ by close price (asymmetric effect)

\begin{tabular}{|c|c|c|c|c|c|}
\hline & Win $\left(\beta_{W}\right)$ & Lose $\left(\beta_{L}\right)$ & & Win $\left(\beta_{W}\right)$ & Lose $\left(\beta_{L}\right)$ \\
\hline \multicolumn{3}{|c|}{ Panel A - DV: MAR_US } & \multicolumn{3}{|c|}{ Panel B - DV: MAR_beta } \\
\hline \multirow{2}{*}{$17^{\text {th }}$} & 0.01 & 4.E-03 & \multirow{2}{*}{$17^{\text {th }}$} & 0.01 & 4.E-03 \\
\hline & $(-0.14)$ & $(-0.34)$ & & $(-0.14)$ & $(-0.35)$ \\
\hline \multirow{2}{*}{$18^{\text {th }}$} & 1.E-04 & $-3 . \mathrm{E}-03$ & \multirow{2}{*}{$18^{\text {th }}$} & 1.E-04 & $-3 . \mathrm{E}-03$ \\
\hline & $(-0.95)$ & $(-0.26)$ & & $(-0.96)$ & $(-0.26)$ \\
\hline \multirow{2}{*}{$19^{\text {th }}$} & 2.E-03 & $-1 . \mathrm{E}-03$ & \multirow{2}{*}{$19^{\text {th }}$} & 2.E-03 & $-1 . \mathrm{E}-03$ \\
\hline & $(-0.38)$ & $(-0.59)$ & & $(-0.38)$ & $(-0.59)$ \\
\hline \multirow{2}{*}{$20^{\text {th }}$} & 0.02 & $-3 . \mathrm{E}-03$ & \multirow{2}{*}{$20^{\text {th }}$} & 0.02 & $-3 . \mathrm{E}-03$ \\
\hline & $(-0.15)$ & $(-0.23)$ & & $(-0.15)$ & $(-0.23)$ \\
\hline \multicolumn{3}{|c|}{ Panel C - DV: MAR_US_MSCI } & \multicolumn{3}{|c|}{ Panel D - DV: MAR_beta_MSCI } \\
\hline \multirow{2}{*}{$18^{\text {th }}$} & 6.E-04 & $-2 . \mathrm{E}-03$ & \multirow{2}{*}{$18^{\text {th }}$} & 6.E-04 & $-2 . \mathrm{E}-03$ \\
\hline & $(-0.74)$ & $(-0.39)$ & & $(-0.75)$ & $(-0.38)$ \\
\hline \multirow{2}{*}{$19^{\text {th }}$} & 1.E-03 & $-8 . \mathrm{E}-04$ & \multirow{2}{*}{$19^{\text {th }}$} & 1.E-03 & $-8 . \mathrm{E}-04$ \\
\hline & $(-0.52)$ & $(-0.7)$ & & $(-0.52)$ & $(-0.68)$ \\
\hline \multirow{2}{*}{$20^{\text {th }}$} & 2.E-03 & $-3 . \mathrm{E}-04$ & \multirow{2}{*}{$20^{\text {th }}$} & 2.E-03 & $-3 . \mathrm{E}-04$ \\
\hline & $(-0.63)$ & $(-0.45)$ & & $(-0.61)$ & $(-0.43)$ \\
\hline
\end{tabular}

Therefore, this paper conjectures that most games end before the stock market opens, and the stock market is efficient to react any information rapidly in the stock market opens (e.g., the game ended on t day night, the effect is reacted on the open price on $t+1$ day). This paper only observes the matches, which is end before the stock market opens, to investigate the effect, and uses the open price to estimate $E R$ and $M A R$. This paper finds that most $\left|\beta_{W}\right|$ are lower than $\left|\beta_{L}\right|$, but it is still insignificant to support Asymmetric effect hypothesis (see Table 6).

$$
\begin{gathered}
E R=R R-R_{f} \\
R_{i t}=\sum_{i=1}^{t} \gamma_{0}+\gamma_{1} R_{i t-1}+\gamma_{2} R_{m t-1}+\gamma_{3} R_{m t}+\gamma_{4} R_{m t+1}+\gamma_{5} D_{t}+\gamma_{6} Q_{t}+\gamma_{7} D_{u s, u p}+\gamma_{8} D_{u s, \text { down }}+\gamma_{9} D_{c, u p}+\gamma_{10} D_{c, \text { down }}+\varepsilon_{i t} \\
\varepsilon_{i t}=\sum_{i=1}^{\beta_{0}+\beta_{W} W_{i t}+\beta_{L} L_{i t}+u_{i t}}
\end{gathered}
$$

Table 6. Empirical results of $E R$ by open price (asymmetric effect)

\begin{tabular}{ccc}
\hline & DV: ER_US & \\
\hline \multirow{2}{*}{$17^{\text {th }}$} & Win $\left(\beta_{W}\right)$ & Lose $\left(\beta_{L}\right)$ \\
& $-4 . \mathrm{E}-03$ & $2 . \mathrm{E}-03$ \\
$18^{\text {th }}$ & $(0.02)$ & $(0.54)$ \\
& $-2 . \mathrm{E}-03$ & $2 . \mathrm{E}-03$ \\
$19^{\text {th }}$ & $(0.18)$ & $(0.46)$ \\
& $-1 . \mathrm{E}-03$ & $-1 . \mathrm{E}-03$ \\
$20^{\text {th }}$ & $(0.66)$ & $(0.77)$ \\
& $-3 . \mathrm{E}-03$ & $2 . \mathrm{E}-03$ \\
& $(0.27)$ & $(0.69)$ \\
\hline
\end{tabular}

Again, this paper considers four situations of MAR to evaluate Asymmetric effect hypothesis. This paper uses MAR as dependent variable of equation (2), and separately uses open price of Dow Jones index and MSCI world index to estimate $R_{m t-1}, R_{m t}$, and $R_{m t+1}$. Although, most $\left|\beta_{L}\right|$ are higher than $\left|\beta_{W}\right|$, the $t$-values are insignificant, and this result still do not support Asymmetric effect hypothesis (see Table 7). 


$$
\begin{gathered}
M A R_{-} U S=R R-R R_{U S} \\
M A R \_ \text {beta_US }=R R-\beta_{U S} R R_{U S} \\
R_{i t}=\sum_{i=1}^{t} \gamma_{0}+\gamma_{1} R_{i t-1}+\gamma_{2} R_{m t-1}+\gamma_{3} R_{m t}+\gamma_{4} R_{m t+1}+\gamma_{5} D_{t}+\gamma_{6} Q_{t}+\gamma_{7} D_{u s, u p}+\gamma_{8} D_{u s, d o w n}+\gamma_{9} D_{c, u p}+\gamma_{10} D_{c, d o w n}+\varepsilon_{i t} \\
\varepsilon_{i t}=\sum_{i=1}^{t} \beta_{0}+\beta_{W} W_{i t}+\beta_{L} L_{i t}+u_{i t}
\end{gathered}
$$

Table 7. Empirical results of MAR by open price (asymmetric effect)

\begin{tabular}{ccc}
\hline & Win $\left(\beta_{W}\right)$ & Lose $\left(\beta_{L}\right)$ \\
\hline & Panle A - DV: MAR_US & \\
$17^{\text {th }}$ & $1-\mathrm{E}-03$ & $-3 . \mathrm{E}-03$ \\
& $(0.71)$ & $(0.52)$ \\
$18^{\text {th }}$ & $-3 . \mathrm{E}-03$ & $8 . \mathrm{E}-04$ \\
& $(0.21)$ & $(0.8)$ \\
$19^{\text {th }}$ & $-6 . \mathrm{E}-04$ & $2 . \mathrm{E}-03$ \\
& $(0.75)$ & $(0.48)$ \\
$20^{\text {th }}$ & $2 . \mathrm{E}-03$ & $1 . \mathrm{E}-03$ \\
& $(0.66)$ & $(0.34)$ \\
& Panel B - DV: MAR_beta & $-3 . \mathrm{E}-03$ \\
$17^{\text {th }}$ & $1-\mathrm{E}-03$ & $(0.52)$ \\
& $(0.7)$ & $8 . \mathrm{E}-04$ \\
$18^{\text {th }}$ & $-3 . \mathrm{E}-03$ & $(0.79)$ \\
& $(0.21)$ & $2 . \mathrm{E}-03$ \\
$19^{\text {th }}$ & $-6 . \mathrm{E}-04$ & $(0.48)$ \\
& $(0.75)$ & $1 . \mathrm{E}-03$ \\
$20^{\text {th }}$ & $2 . \mathrm{E}-03$ & $(0.34)$ \\
& $(0.65)$ &
\end{tabular}

Description: This paper cannot acquire the open price of the MSCI world index from the database.

Until now, our results have not supported Asymmetric effect hypothesis. Therefore, this paper observes on each match from group games to championship games to evaluate the effect. This paper divides the data into two groups, and uses the close price of the local stock market to estimate $E R$. This paper then puts the data into equation (2) separately. The empirical results show that only a few matches are significant. However, the result of each match still do not support Asymmetric effect hypothesis.

This paper further conjectures that only extreme wins and extreme loses strongly affect the excess stock returns. Therefore, this paper sort out the matches, of which the scores largely differ between contestants. This paper uses both close and open prices of the local stock market to estimate $E R$ and the close and open prices of the Dow Jones and the close price of MSCI to calculate $R_{m t-l}, R_{m t}$, and $R_{m t+l}$. This paper then puts the data into equation (2). However, most results are insignificant, and Asymmetric effect hypothesis is still not supported (see Table 8).

$$
\begin{gathered}
E R=R R-R_{f} \\
R_{i t}=\sum_{i=1}^{t} \gamma_{0}+\gamma_{1} R_{i t-1}+\gamma_{2} R_{m t-1}+\gamma_{3} R_{m t}+\gamma_{4} R_{m t+1}+\gamma_{5} D_{t}+\gamma_{6} Q_{t}+\gamma_{7} D_{u s, u p}+\gamma_{8} D_{u s, d o w n}+\gamma_{9} D_{c, u p}+\gamma_{10} D_{c, d o w n}+\varepsilon_{i t} \\
\varepsilon_{i t}=\sum_{i=1}^{t} \beta_{0}+\beta_{W} W_{i t}+\beta_{L} L_{i t}+u_{i t}
\end{gathered}
$$


Table 8. Empirical result of extreme wins and loses

\begin{tabular}{|c|c|c|c|}
\hline & Extreme Wins $\left(D_{W}\right)$ & Extreme Loses $\left(D_{L}\right)$ & Extreme Wins and Loses (D) \\
\hline \multicolumn{4}{|c|}{ Panel A - ER_US (Close Price) } \\
\hline \multirow{2}{*}{$17^{\text {th }}$} & $-2.1 \mathrm{E}-03$ & $-4.3 \mathrm{E}-03$ & $2.2 \mathrm{E}-03$ \\
\hline & $(-0.15)$ & $(-0.3)$ & $(-0.66)$ \\
\hline \multirow{2}{*}{$18^{\text {th }}$} & 0.01 & 0.01 & 5.9E-04 \\
\hline & $(-0.68)$ & $(-0.63)$ & $(-0.14)$ \\
\hline \multirow{2}{*}{$19^{\text {th }}$} & $2.2 \mathrm{E}-03$ & $-1.1 \mathrm{E}-03$ & $1.3 \mathrm{E}-03$ \\
\hline & $(-0.18)$ & $(-0.1)$ & $(-0.28)$ \\
\hline \multirow{2}{*}{$20^{\text {th }}$} & 0.05 & 0.03 & $4.6 \mathrm{E}-04$ \\
\hline & $(-0.51)$ & $(-0.42)$ & $(-0.32)$ \\
\hline \multicolumn{4}{|c|}{ Panel B - ER_US (Open Price) } \\
\hline \multirow{2}{*}{$17^{\text {th }}$} & $-9.4 \mathrm{E}-09$ & $-3.8 \mathrm{E}-08$ & $1.4 \mathrm{E}-08^{\mathrm{b}}$ \\
\hline & $(-0.41)$ & $(-1.47)$ & $(-2.54)$ \\
\hline \multirow{2}{*}{$18^{\text {th }}$} & 4.E-03 & $3.97 \mathrm{E}-03$ & 2.E-04 \\
\hline & $(-1.03)$ & $(-1.01)$ & $(-0.25)$ \\
\hline \multirow{2}{*}{$19^{\text {th }}$} & $3.1 \mathrm{E}-03$ & 0.01 & $-1.3 \mathrm{E}-03$ \\
\hline & $(-0.51)$ & $(-0.79)$ & $(-0.81)$ \\
\hline \multirow{2}{*}{$20^{\text {th }}$} & $3.5 \mathrm{E}-03$ & $3.4 \mathrm{E}-03$ & 2.E-03 \\
\hline & $(-0.63)$ & $(-0.55)$ & $(-0.52)$ \\
\hline \multicolumn{4}{|c|}{ Panel C-ER_MSCI (Close price) } \\
\hline \multirow{2}{*}{$18^{\text {th }}$} & 0.02 & 0.03 & -0.01 \\
\hline & $(-0.52)$ & $(-1.11)$ & $(-1.7)$ \\
\hline \multirow{2}{*}{$19^{\text {th }}$} & -0.01 & -0.01 & $1.2 \mathrm{E}-03$ \\
\hline & $(-0.38)$ & $(-0.46)$ & $(-0.27)$ \\
\hline \multirow{2}{*}{$20^{\text {th }}$} & 0.03 & -0.05 & 0.02 \\
\hline & $(-0.67)$ & $(-0.78)$ & $(-0.42)$ \\
\hline
\end{tabular}

Description: (1) This paper cannot acquire the open price of the MSCI world index from the database; (2) a, b, and c denote the significant levels of $10 \%, 5 \%$, and $1 \%$.

This paper combines all matches together to evaluate Asymmetric effect hypothesis again. However, the results do not support Asymmetric effect hypothesis.

This paper investigates Persistent effect hypothesis by using equations (2) and (3), and use both close and open prices to calculate $E R$ ( $E R$ is considered a dependent variable of equation (2)), and separately uses the Dow Jones index to estimate $R_{m t-1}, R_{m t}$, and $R_{m t+1}$. This paper divides the data of win into two groups, the previous games is win or lose. This paper uses these two groups to examine the effects of stock markets in the situations of if this game is win and the previous games is win $\left(\beta_{W W}\right)$ or lose $\left(\beta_{W L}\right)$ (equation (3)). If the effect of Persistent effect hypothesis is supported, $\left|\beta_{W W}\right|$ must be lower than $\left|\beta_{W L}\right|$. This paper separates the data of lose into two groups, the previous games is win or lose. This paper uses these two groups to investigate the effects of stock markets in the situations of if this game is lose and the previous games is win $\left(\beta_{L W}\right)$ or lose $\left(\beta_{L L}\right)$ (equation (3)). If Persistent effect hypothesis is supported, $\left|\beta_{L W}\right|$ must be higher than $\left|\beta_{L L}\right|$. The empirical results of the previous games effect show that most $\left|\beta_{W W}\right|$ are lower than $\left|\beta_{W L}\right|$, and $\left|\beta_{L W}\right|$ are higher than $\left|\beta_{L L}\right|$. However, the results are insignificant, and Persistent effect hypothesis is not supported (see Table 9). 


$$
\begin{gathered}
E R=R R-R_{f} \\
R_{i t}=\sum_{i=1}^{t} \gamma_{0}+\gamma_{1} R_{i t-1}+\gamma_{2} R_{m t-1}+\gamma_{3} R_{m t}+\gamma_{4} R_{m t+1}+\gamma_{5} D_{t}+\gamma_{6} Q_{t}+\gamma_{7} D_{u s, u p}+\gamma_{8} D_{u s, d o w n}+\gamma_{9} D_{c, u p}+\gamma_{10} D_{c, d o w n}+\varepsilon_{i t} \\
\varepsilon_{i t}=\sum_{i=1}^{t} \beta_{0}+\beta_{W} W_{i t}+\beta_{L} L_{i t}+u_{i t}
\end{gathered}
$$

\begin{tabular}{|c|c|c|c|c|}
\hline \multirow{2}{*}{$\begin{array}{c}\text { Previous games } \\
\text { This game }\end{array}$} & \multicolumn{2}{|c|}{ Win } & \multicolumn{2}{|c|}{ Lose } \\
\hline & $\operatorname{Win}\left(\beta_{W W}\right)$ & Lose $\left(\beta_{W L}\right)$ & Win $\left(\beta_{L W}\right)$ & Lose $\left(\beta_{L L}\right)$ \\
\hline \multicolumn{5}{|c|}{ Panel A - DV: ER_US (Close price) } \\
\hline \multirow{2}{*}{$17^{\text {th }}$} & 4.E-03 & 9.E-04 & 0.01 & -0.01 \\
\hline & $(0.29)$ & $(0.88)$ & $(0.01)$ & $(0.05)$ \\
\hline \multirow{2}{*}{$18^{\text {th }}$} & $-2 . \mathrm{E}-03$ & $-3 . \mathrm{E}-03$ & $-3 . E-03$ & -0.01 \\
\hline & $(0.17)$ & $(-0.81)$ & $(0.17)$ & $(0.26)$ \\
\hline \multirow{2}{*}{$19^{\text {th }}$} & $-2 . \mathrm{E}-03$ & $-4 . E-04$ & -9.E-04 & 3.E-03 \\
\hline & $(0.32)$ & $(-0.94)$ & $(0.68)$ & $(0.44)$ \\
\hline \multirow{2}{*}{$20^{\text {th }}$} & 3.E-03 & $-4 . E-03$ & 0.03 & 0.02 \\
\hline & $(0.36)$ & $(-0.77)$ & $(0.14)$ & $(0.05)$ \\
\hline \multicolumn{5}{|c|}{ Panle B - DV: ER_US (Open price) } \\
\hline \multirow{2}{*}{$17^{\text {th }}$} & $-3 . \mathrm{E}-03$ & $-3 . \mathrm{E}-04^{\mathrm{a}}$ & $-1 . E-05$ & $-2 . E-04$ \\
\hline & $(-0.2)$ & $(-1.66)$ & $(-1.01)$ & $(-0.85)$ \\
\hline \multirow{2}{*}{$18^{\text {th }}$} & $-2 . \mathrm{E}-03$ & 4.E-03 & 3.E-03 & 1.E-04 \\
\hline & $(0.44)$ & $(0.28)$ & $(0.31)$ & $(0.92)$ \\
\hline \multirow{2}{*}{$19^{\text {th }}$} & $-2 . E-03$ & 1.E-03 & $-3 . E-04$ & - \\
\hline & $(0.35)$ & $(0.84)$ & $(-0.94)$ & \\
\hline \multirow{2}{*}{$20^{\text {th }}$} & $-3 . \mathrm{E}-03$ & 4.E-03 & 2.E-03 & -1.E-03 \\
\hline & $(-0.36)$ & $(0.48)$ & $(0.42)$ & $(-0.76)$ \\
\hline
\end{tabular}

Table 9. Empirical results of previous games effect

Description: There is no situation of both this game and previous games were lose in the $19^{\text {th }}$ FIFA World Cup (2010).

Up to now, this paper has not found significant effects in the aforementioned empirical results to support our hypothesis. Therefore, this paper argues that the results of the FIFA World Cup strongly affect the championship games and excess stock returns of the team's sport sponsor companies, instead of local stock market return. Therefore, this paper investigates the relation between the results of the championship games and sport sponsors' excess stock returns for estimating Sponsor effect hypothesis. This paper chose the sport (sponsors) companies of the team in the championship games, and uses both close and open prices of the team's sponsor stock index to calculate $R R$ and MAR to investigate the effect of sport sentiments on excess stock returns. The empirical results of the championship games show that sport sentiments positively affect the excess stock returns of a team's sponsor when the team won the championship, and negatively affect the excess stock returns of a team's sponsor when the team loses the championship (see Table 10 and $11)$.

$$
\begin{gathered}
R R_{\text {close }}=\left(\text { close }_{\text {price }}-\text { close }_{\text {price }} t-1\right) / \text { close }_{\text {price }} t-1 \\
M A R=R R-R R_{U S}
\end{gathered}
$$


Table 10. Empirical result of championship games by close price

\begin{tabular}{|c|c|c|c|c|c|c|}
\hline \multicolumn{7}{|c|}{ Panel A - 2002 Championship Games - Brazil (2) vs. Germany (0) } \\
\hline Sponsors & \multicolumn{2}{|c|}{ Brazil - Nike } & \multicolumn{2}{|c|}{ Germany - Adidas } & \multicolumn{2}{|c|}{$t$-value } \\
\hline Date & Ret.close & Adj. Ret.close & Ret.close & Adj. Ret.close & Ret.close $_{\text {- }}$ & Adj. Ret.close \\
\hline $2002 / 7 / 1$ & $1.77 \%$ & $3.21 \%$ & $-0.84 \%$ & $0.60 \%$ & 1.14 & 1.14 \\
\hline \multicolumn{7}{|c|}{ Panel B - 2006 Championship Games - Italy (5) vs. France (3) } \\
\hline Sponsors & \multicolumn{2}{|c|}{ Italy - Puma } & \multicolumn{2}{|c|}{ France - Nike } & \multicolumn{2}{|c|}{$t$-value } \\
\hline Date & Ret.close & Adj. Ret.close & Ret.close & Adj. Ret.close & Ret.close $_{\text {- }}$ & Adj. Ret.close \\
\hline 2006/7/10 & $0.73 \%$ & $0.62 \%$ & $-0.13 \%$ & $-0.24 \%$ & -0.014 & -0.12 \\
\hline \multicolumn{7}{|c|}{ Panel C - 2010 Championship Games - Spain (1) vs. Netherland (0) } \\
\hline Sponsors & \multicolumn{2}{|c|}{ Spain - Adidas } & \multicolumn{2}{|c|}{ Netherlands - Nike } & \multicolumn{2}{|c|}{$t$-value } \\
\hline Date & Ret.close & Adj. Ret.close & Ret.close & Adj. Ret.close & Ret.close & Adj. Ret.close \\
\hline 2010/7/12 & $-0.30 \%$ & $-0.47 \%$ & $-0.48 \%$ & $-0.66 \%$ & -0.14 & -0.33 \\
\hline
\end{tabular}

Description: This paper does not consider the $20^{\text {th }}$ FIFA World Cup (2014) to estimate the effect of sport sentiments on sponsors' excess stock returns because Germany and Argentina have the same sponsors.

$$
\begin{gathered}
R R_{\text {open }}=\left(\text { open price }_{t}-\text { close }_{\text {price }} \text { }_{t-1}\right) / \text { close }_{\text {price }} t-1 \\
M A R=R R-R R_{U S}
\end{gathered}
$$

\begin{tabular}{|c|c|c|c|c|c|c|}
\hline Date & Ret. $_{\text {open }}$ & Adj. Ret. ${ }_{\text {open }}$ & Ret. open & Adj. Ret. open & Ret. $_{\text {open }}$ & Adj. Ret. open \\
\hline \multicolumn{7}{|c|}{ Panel A - 2002 Championship Games - Brazil (2) vs. Germany (0) } \\
\hline Sponsors & \multicolumn{2}{|c|}{ Brazil - Nike } & \multicolumn{2}{|c|}{ Germany - Adidas } & \multicolumn{2}{|c|}{$t$-value } \\
\hline $2002 / 7 / 1$ & $1.30 \%$ & $1.64 \%$ & $-0.30 \%$ & $-0.03 \%$ & $1.85^{\mathrm{a}}$ & $1.85^{\mathrm{a}}$ \\
\hline \multicolumn{7}{|c|}{ Panel B - 2006 Championship Games - Italy (5) vs. France (3) } \\
\hline Sponsors & \multicolumn{2}{|c|}{ Italy - Puma } & Fra & Nike & \multicolumn{2}{|c|}{$t$-value } \\
\hline $2006 / 7 / 10$ & $0.38 \%$ & $1.22 \%$ & $-2.47 \%$ & $-1.63 \%$ & $-1.72^{\mathrm{a}}$ & $-1.71^{\mathrm{a}}$ \\
\hline \multicolumn{7}{|c|}{ Panel C - 2010 Championship Games - Spain (1) vs. Netherlands (0) } \\
\hline Sponsors & \multicolumn{2}{|c|}{ Spain - Adidas } & Nethe & ls - Nike & \multicolumn{2}{|c|}{$t$-value } \\
\hline $2010 / 7 / 12$ & $2.32 \%$ & $1.72 \%$ & $-0.44 \%$ & $-1.05 \%$ & $1.85^{\mathrm{a}}$ & $1.84^{\mathrm{a}}$ \\
\hline
\end{tabular}

Table 11. Empirical result of championship games by open price

Description: (1) This paper does not consider the $20^{\text {th }}$ FIFA World Cup (2014) to estimate the effect of sport sentiments on sponsors' excess stock returns because Germany and Argentina have the same sponsors; (2) the date is mean the next trading day after game day; (3) $t$-value is calculated by excess stock returns of one to ten days before game day and next trading day after game day between champion and runner-up; (4)a, b, and c denote that the significant levels of $10 \%$, $5 \%$, and $1 \%$.

Similar to previous studies, this paper finds an inconsistent relation between sport sentiments and excess stock returns. For instance, excess stock returns of local stock markets are negatively affected after a participant country won the competition (Berument et al. 2009; Palomino et al., 2009). There is no significant effect between the results of the European Championship and excess stock returns (Klein et al. 2009). Edmans et al. (2007) reveal an asymmetric effect, which is a significant negative effect on local markets after loses and an insignificant effect after wins. This paper considers seven conditions: (1) Considering stock markets are efficient markets, this paper uses not only close price but also open price to estimate excess stock returns; (2) This paper further considers that sport sentiments affect sponsors' excess stock returns; (3) This paper further considers a time-lagged effect between sports sentiment and excess stock returns; (4) This paper further considers the persistent effect of previous games result; (5) This paper further considers further considers the samples include all participant countries and each of participant countries; (6) This paper considers the situations of extreme wins and extreme loses; (7) This paper further considers the sample of championship games to exam the relation between sport sentiments and excess stock returns.

This paper finds no relation between sport sentiments and excess stock returns, and this result is consistent with that of Klein et al. (2009). In contrast to Klein (2009), this paper uses the FIFA World Cup as our data, both close and open prices to estimate $E R$ and four types of $M A R$ as dependent variables; this paper also controls the effect of the previous game results, considers the situations of the participant countries and single countries, considers extreme wins and extreme loses.

Therefore, this paper considers the sport (sponsor) company, and investigates the relation between sport sentiments and excess stock returns of a sponsor company. This paper finds a significant positive effect after win and a significant negative effect after lose in the championship games, and this effect only occurs on the open price of the next trading day. For example, the championship game of $17^{\text {th }}$ FIFA World Cup was started in June $30^{\text {th }} 2002$ evening, the match was played by Brazil and Germany, and Brazilian team won the champion in the end. The sport sponsor company of Brazilian team was Nike, and Nike's stock return of open price on first trading day after victory rose 1.3 percent, and 
Nike's stock return of open price on second trading day was zero. From the other point of view, Adidas was the sport (sponsor) company of German team, and Adidas' stock return of close price on first trading day after loss slumps 0.84 percent, and declines continuously for three trading days after loss. However, Adidas' stock return of open price on first trading day after loss slumps 0.3 percent, and Nike's stock return of open price on second trading day slumps 1.67 percent. Therefore, sport sentiments is an efficient effect, and only occurs on the open price of the next trading day, moreover, sport sentiments possibly has a positive quick effect after victory and negative persistent effect after loss.

\section{Conclusion}

This paper investigates the relation between sport sentiments and excess stock returns by using an equation proposed by Edmans et al. (2007). This paper proposes three hypotheses, Asymmetric effect hypothesis, Persistent effect hypothesis, and Sponsor effect hypothesis. In Addition, this paper separately uses ER and four types of MAR as our dependent variables, and close and open prices to estimate $E R$ and $M A R$.

This paper uses numerous programmes to investigate the relation between sport sentiments and excess stock returns. The excess stock returns are affected by sport sentiments. However, most effects are insignificant. Therefore, this paper argues that the results of FIFA World Cup strongly affect the championship games and the excess stock returns of the sport (sponsors) companies, instead of local stock market returns. This paper finds that Sponsor effect hypothesis is supported which means that the excess stock returns of the sponsors have a positive (negative) effect on the first or second trading day after the team won (lose) the championship games. In sum, this paper proposes that investors are rational in dealing with sport sentiments (FIFA World Cup) and the stock trading decision. This means that although fans feel depressed after their favourite team is eliminated, they would not make an irrational decision to lose their money on the stock market. Therefore, investors' trading decisions on the stock market are not be influenced by the results of FIFA World Cup, that is, the local stock market returns are not influenced by the results of the FIFA World Cup. However, the results of the FIFA World Cup have momentary effect on the open price of the sport (sponsor) company on the next trading day. These empirical results can offer an important information for the investors of sport sponsor stocks. Finally, this paper provides directions for future research. Previous studies often state that sport sentiments influences local excess stock returns. However, sport sentiments is not likely to strongly affect the local stock market returns. Future research could consider determining whether individual excess stock returns are affected by sport sentiments or adopt a different methodology to test the relation between sport sentiments and excess stock returns. This paper only considers the FIFA World Cup as our data. Different result may be obtained for other sports. Future studies should consider this option.

\section{References}

Arkes, H., Herren, L., \& Isen, A. (1988). The role of potential loss in the influence of affect on risk-taking behavior, Organizational Behavior and Human Decision Processes, 42, 181-193. http://dx.doi.org/10.1016/0749-5978(88)90011-8

Ashton, J. K., Gerrard, B., \& Hudson, R. (2003). Economic impact of national sporting success: evidence from the London stock exchange, Applied Economics Letters, 10(12), 783-785. http://dx.doi.org/10.1080/1350485032000126712

Ashton, J. K., Gerrard, B., \& Hudson, R., (2011). Do national soccer results really impact on the stock market? Applied Economics, 43, 3709-3717. http://dx.doi.org/10.1080/00036841003689762

Berument, M., Ceylan, N., \& Ogut-Eker, G. (2009). Soccer, stock returns and fanaticism: evidence from Turkey, The Social Science Journal, 46, 594-600. http://dx.doi.org/10.1016/j.soscij.2009.06.001

Berument, M., Ceylan, N., \& Ogut-Eker, G. (2013). Football and the Risk-Return Relationship for a Stock Market: Borsa Istanbul, Emerging Markets Finance and Trade, 49(2), 19-30. http://dx.doi.org/10.2753/REE1540-496X490202

Chang, S. C., Chen, S. S., Chou, R., \& Lin, Y. (2013). Local sports sentiment and returns of locally headquartered stocks: A firm-level analysis, Journal of Empirical Finance, 19, 309-318. http://dx.doi.org/10.1016/j.jempfin.2011.12.005

Cialdini, R., Borden, R., Thorne, A., Walker, M., Freeman, S., \& Sloan, L. (1976). Basking in reflected glory: three (football) field studies, Journal of Personality and Social Psychology, 34(3), 366-375. http://dx.doi.org/10.1037/0022-3514.34.3.366

Edmans, A., García, D., \& Norli, Ø. (2007). Sports sentiment and stock returns, The Journal of Finance, 62(4), 1967-1998. http://dx.doi.org/10.1111/j.1540-6261.2007.01262.x

Fung, K. W., Demir, E., Lau, C. K., \& Chan, K. H. (2015). Reexamining sports-sentiment hypothesis: Microeconomic evidences from Borsa Istanbul, Journal of International Financial Markets, Institutions and Money, 34, 337-355. 
http://dx.doi.org/10.1016/j.intfin.2014.11.015

Gerlach, J. (2011). International sports and investor sentiment: do national team matches really affect stock market returns?Applied Financial Economics, 21(12), 863-880. http://dx.doi.org/10.1080/09603107.2010.543069

Hanke, M. \& Kirchler M. (2013). Football championships and jersey sponsors' stock prices: an empirical investigation, The European Journal of Finance, 19(3), 228-241. http://dx.doi.org/10.1080/1351847X.2012.659268

Hirt, E., Erickson, G., Kennedy, C., \& Zillmann, D. (1992). Costs and benefits of allegiance: changes in fans' self-ascribed competencies after team victory versus defeat, Journal of Personality and Social Psychology, 63, 724-738. http://dx.doi.org/10.1037/0022-3514.63.5.724

Kahneman, D., \& Tversky, A. (1979). Prospect theory: an analysis of decision under risk, Econometrica, 47, $263-292$. http://dx.doi.org/10.2307/1914185

Kaplanski, G., \& Levy, H. (2008). Exploitable Predictable Irrationality: The FIFA World Cup Effect on the U.S. Stock Market, Journal of Financial and Quantitative Analysis, 45(2), 535-553. http://dx.doi.org/10.1017/S0022109010000153

Kim, C., \& Park, J. (1994). Holiday effects and stock returns: further evidence, Journal of Financial and Quantitative Analysis, 29(1), 145-157. http://dx.doi.org/10.2307/2331196

Klein, C., Zwergel, B., \& Heiden, S. (2009). On the existence of sports sentiment: the relation between football match results and stock index returns in Europe, Review of Managerial Science, 3, 191-208. http://dx.doi.org/10.1007/s11846-009-0031-8

Lee, J., Shen, C., \& Yen, P. (2010). Fund investors' disposition effect vis-à-vis herding redemption and non-herding redemption using quantile regression least square dummy variable estimator, Journal of Management and Systems, 17(1), 1-26.

Madrigal, R. (2001). Social identity effects in a belief attitude-intentions hierarchy: implications for corporate sponsorship, Psychology and Marketing, 18(2), 145-65.

http://dx.doi.org/10.1002/1520-6793(200102)18:2<145::AID-MAR1003>3.0.CO;2-T

Markman, K., \& Hirt, E. (2002). Social prediction and the "allegiance bias, Social Cognition, 20, 58-86. http://dx.doi.org/10.1521/soco.20.1.58.20943

Palomino, F., Renneboog, L., \& Zhang, C. (2009). Information salience, investor sentiment, and stock returns: the case of British soccer betting, Journal of Corporate Finance, 15, 368-387.

Schweitzer, K., Zillmann, D., Weaver, J., \& Luttrell, E. (1992). Perception of threatening events in the emotional aftermath of a televised college football game, Journal of Broadcasting and Electronic Media, 36, 75-82. http://dx.doi.org/10.1016/j.jcorpfin.2008.12.001

Stracca, L. (2004). Behavioral finance and asset prices: where do we stand? Journal of Economic Psychology, 25(3), 373-405. http://dx.doi.org/10.1016/S0167-4870(03)00055-2

Wann, D. L., \& Branscombe, N. R. (1993). Sports fans: measuring degree of identification with the team, International Journal of Sport Psychology, 24, 1-17.

Wann, D., Dolan, T., Mcgeorge, K., \& Allison, J. (1994). Relationships between spectator identification and spectators' perceptions of influence, spectators' emotions, and competition outcome, Journal of Sport and Exercise Psychology, 16, 347-364.

Yu, J., \& Yuan, Y. (2011). Investor sentiment and the mean-variance relation, Journal of Financial Economics, 100, 367-381. http://dx.doi.org/10.1016/j.jfineco.2010.10.011

\section{Copyrights}

Copyright for this article is retained by the author(s), with first publication rights granted to the journal.

This is an open-access article distributed under the terms and conditions of the Creative Commons Attribution license which permits unrestricted use, distribution, and reproduction in any medium, provided the original work is properly cited. 